\title{
A Comparative Study between Silver Based Dressing and Vacuum Dressing in Management of Diabetic Foot
} Infection

A.S.Ezzat, A.H.Abl El-Maqsood, R.S.Salama and M.E.Mahmoud General Surgery Dept., Faculty of Medicine, Benha Univ., Benha, Egypt

E-Mail: Ehab11@gmail.com

\begin{abstract}
For centuries silver was presented to the population as an active ingredient for sanitation and food protection against bacteria but in these recent years it has been introduced for wound care management as antibacterial agent. Vacuum dressing is a new technique of dressing Also called Negative-pressure wound therapy [NPWT] using a device to make continuous suction over an open wound decreasing edema and secretions, promotes healing and granulation tissue fast growing. We aimed to compare between silver based dressing and vacuum dressing in management of diabetic foot infection 50 Patients ages from 50-65 years old having diabetic foot Infection, on insulin injections and undergoing treatment. All patients had prober surgical debridement and wound irrigation using normal saline $0.9 \%$ and povidone iodine, then they will be subdivided into 2 groups those in the first group will have silver containing ointment afterward. The second group will have silver based dressing using vacuum dressing. There were no difference between the two groups in healing percentage [84\%] in the two groups and number of patients needed higher amputation were equal in both groups 3 cases in each group [16\%], although there was significance difference in wound size at the end of the study between silver group and vacuum group and rate of healing which was more rapid in the vacuum group. we conclude that vacuum dressing has good healing power and more effective than silver dressing in management of diabetic foot infection. It decreases time needed for wound healing and hospital stay better than silver dressing.
\end{abstract}

\section{Introduction}

Diabetic foot is characterized as the nearness of contamination, ulceration or potentially demolition of profound tissues related with neurologic variations from the norm and different degrees of fringe blood vessel illness [PAD] in the lower appendage in patients with diabetes [1].

Microbiological culture has become a best quality level strategy in recognizing kinds of causative creature and the reasonable anti-toxin to utilize, tissue culture gathered by curettage or biopsy is more solid than old technique q-tip culture [2].

More up to date procedures were acquainted with the market have a promising impact in the field of diabetic foot the board in this examination we will concentrate on 4 unique kinds of dressing that have a decent outcome on taking out contamination and advance mending of the tissues of diabetic foot these four sorts are; 1-vacuum dressing 2-hydrocolloid dressing 3-hydrogel dressing 4-silver based dressing [3].

Vacuum dressing is another method of dressing Also called Negative-pressure wound treatment [NPWT] utilizing a gadget to make consistent attractions over an open injury diminishing edema and discharges, advances recuperating and granulation tissue quickly developing, In 1995, Kinetic Concepts was the main organization to have a NPWT item cleared by the US Food and Drug Administration. Following expanded utilization of the method by emergency clinics in the US, the strategy was endorsed for repayment by the Centers for Medicare and Medicaid Services in 2001 [ 4].

Hydrogels are mind boggling hydrophilic natural cross-connected polymers, comprising of a $80 \%-90 \%$ water base. These gels are accessible in a freestreaming indistinct or fixed adaptable sheet structure. They can assimilate a base measure of liquid by growing, yet they additionally can give dampness to a dry injury, in this manner encouraging autolytic debridement and keeping up a clammy injury condition that is thermally protected. They have additionally been appeared to advance granulation and epithelialization and lessen the temperature of an injury bed by up to $5^{\circ} \mathrm{C}$ [4].

Hydrocolloid dressing is a dark or trasparant sheet of dressing which is usally water verification makes it simple for the patient to have shower. it comprises of cross-connected cement mass containing a scattering of gelatin, gelatin and carboxy-methylcellulose along with different polymers and glues on the dynamic surface. It adds the preferred position to affix mending, decline recurrence of wrapping and bringing down degree of torment [5].

For a considerable length of time silver was introduced to the populace as a functioning element for sterilization and food assurance against microorganisms however in these ongoing years it has been presented for wound consideration the board as antibacterial specialist. The job of silver as antibacterial operator isn't completely comprehended despite the fact that it has been seen that the cation in silver is exceptionally dynamic against gram positive and gram negative microscopic organisms causing cell divider harm and cell shrinkage assuming a significant job during the time spent injury mending [6].

We planned to think about between silver based dressing and vacuum dressing in the executives of diabetic foot disease.

\section{Patients and methods}

All patients remembered for the examination will be submitted to legitimate history taking and clinical evaluation at that point blood tests for; CBC, HBA1c, fasting and post prandial glucose tests, serum creatinine, serum urea and swab culture test from the injury. X-beam will be embraced to the influenced 
appendage with routine blood vessel shading Doppler to all cases to prohibit huge blood vessel stenosis. The individuals who are with critical stenosis will be discarded from the examination. All patients will have prober careful debridement and wound water system utilizing typical saline $0.9 \%$ and povidone iodine, at that point they will be partitioned into 2 gatherings those in the main gathering will have silver containing balm a short time later. The subsequent gathering will have silver based dressing utilizing vacuum dressing.

50 Patients ages from 50-65 years of age having diabetic foot Infection, on insulin infusions and experiencing treatment in the branch of general medical procedure at Luxor International Hospital and Banha University Hospital will be considered in the consideration study.

Incorporation standards was patients with diabetic foot contamination and their ages between 50-65 years of age's and insulin subordinate

Rejection standards was patients with noteworthy blood vessel stenosis and deprived for revascularization, venous ulcer, non-atherosclerotic infections, for example, burger's sickness and vasculitis and the individuals who are on oral hypoglycemic medications instead of insulin.

An all out 50 patient having diabetic foot were incorporated. Clinical appraisal was accomplished for all patient in the wake of conceding them. History and clinical discoveries were taken. following examinations were completed for all patients: routine blood examinations, x-beam, blood vessel shading Doppler, Swab culture affectability. These 50 patients will be partitioned into 2 subgroups, the primary gathering will have vacuum dressing as the backbone of the treatment, the subsequent gathering will have silver based dressing.

\section{Results}

The mean age among group 1 cases were $58.0 \pm 4.4$ years, with males representing $52 \%$ of cases. BTG was the most common type of wound [12\%] and RA was the most common type of surgery [20\%]

Osteomyelitis was present among $64 \%$ of group 1 cases on $\mathrm{X}$ ray, infection was contained in $88 \%$ of cases and healing was detected in $84 \%$ of cases

The mean age among group 2 cases were $58.0 \pm 4.5$ years, with males representing $76 \%$ of cases. MFI was the most common type of wound [12\%] and DE was the most common type of surgery [24\%]

Osteomyelitis was present among $36 \%$ of group 2 cases on $\mathrm{X}$ ray, infection was contained in $84 \%$ of cases and healing was detected in $84 \%$ of cases

There was no significant difference between the two study groups as regard infection and healing, however a significant difference between the two study groups was found as regard osteomyelitis occurrence as $64 \%$ of silver group developed osteomyelitis compared to $36 \%$ of VAC group

Among group 1 cases, there was no significant difference between those with and those without osteomyelitis as regard patients 'age. Similarly, no significant difference between those with and those without infection, healed and non healed cases as regard patients 'age

Among group 1 cases, there was no significant difference between male and female as regard occurrence of osteomyelitis, resolving of infection, or healing of wound

Among group 2 cases, there was no significant difference between those with and those without osteomyelitis as regard patients 'age. Similarly, no significant difference between those with and those without infection, healed and non/ healed cases as regard patients 'age

Among group 2 cases, there was no significant difference between male and female as regard occurrence of osteomyelitis, resolving of infection, or healing of wound

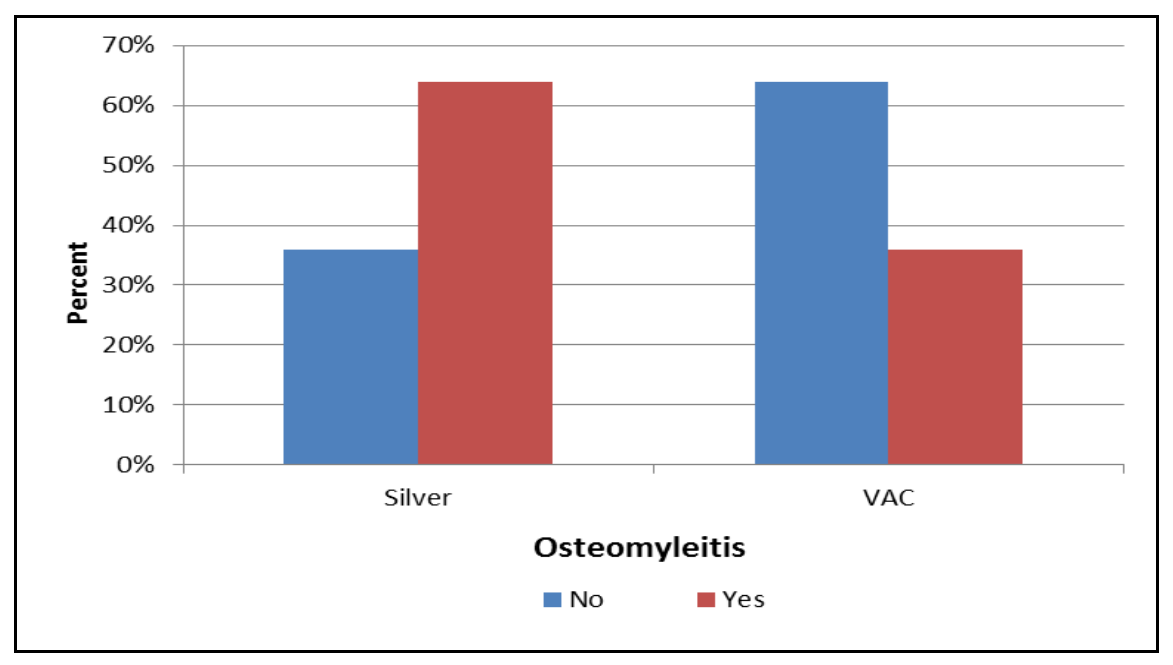

Fig (1) Relation between the two groups about osteomyleities. 


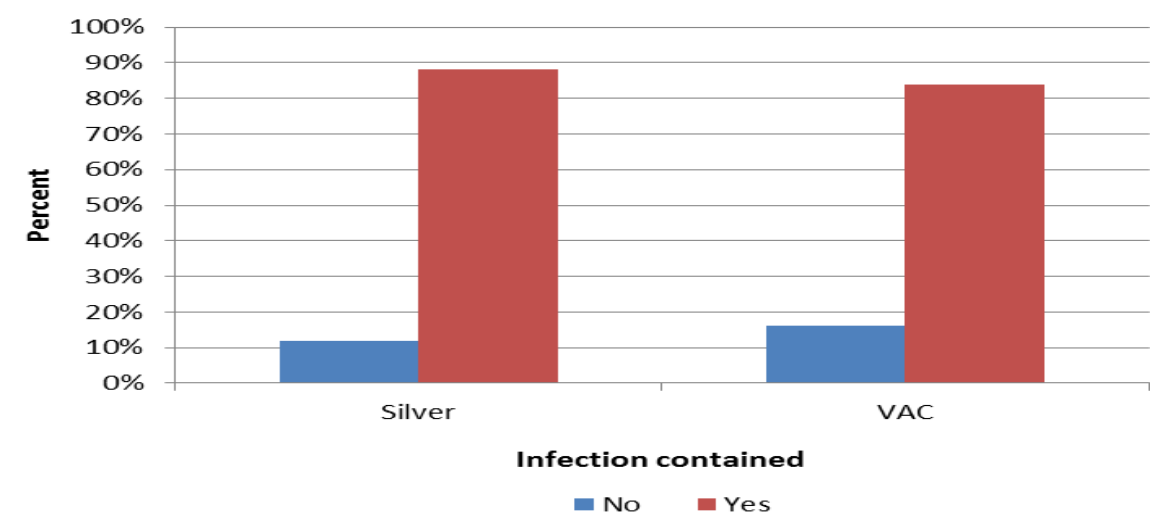

Fig (2) Relation between the two groups about infection contained.

Table (1) Comparison between the two study groups as regard osteomyelitis, infection and healing.

\begin{tabular}{|c|c|c|c|c|c|c|c|}
\hline & & \multicolumn{4}{|c|}{ Group } & \multirow{3}{*}{$\mathbf{P}$} & \multirow{3}{*}{ Sig } \\
\hline & & \multicolumn{2}{|c|}{ Silver } & \multicolumn{2}{|c|}{ VAC } & & \\
\hline & & $\mathbf{N}$ & $\%$ & $\mathbf{N}$ & $\%$ & & \\
\hline \multirow{2}{*}{ X-ray } & No osteomyelitis & 9 & $36.0 \%$ & 16 & $64.0 \%$ & \multirow{2}{*}{$0.048 *$} & \multirow{2}{*}{$\mathrm{S}$} \\
\hline & Osteomyelitis & 16 & $64.0 \%$ & 9 & $36.0 \%$ & & \\
\hline \multirow[t]{2}{*}{ Infection contained } & No & 3 & $12.0 \%$ & 4 & $16.0 \%$ & \multirow{2}{*}{$1.0 * *$} & \multirow{2}{*}{ NS } \\
\hline & Yes & 22 & $88.0 \%$ & 21 & $84.0 \%$ & & \\
\hline \multirow[t]{2}{*}{ FATE } & Non healed & 4 & $16.0 \%$ & 4 & $16.0 \%$ & \multirow{2}{*}{$1.0 * *$} & \multirow{2}{*}{ NS } \\
\hline & Healed & 21 & $84.0 \%$ & 21 & $84.0 \%$ & & \\
\hline
\end{tabular}

*Chi-Square Tests

**Fisher exact

Table (2) Relation between age and each of osteomyelitis, infection and healing among group 1 cases.

\begin{tabular}{llllll}
\hline & & \multicolumn{2}{c}{ Age } & \multirow{2}{*}{ P } & \multirow{2}{*}{ Sig } \\
\cline { 3 - 4 } & & Mean & 林 & & \multirow{2}{*}{ X-ray } \\
\cline { 3 - 4 } & No osteomyelitis & 57.67 & 5.22 & & \multirow{2}{*}{ NS } \\
Infection & Osteomyelitis & 58.19 & 4.05 & & \\
contained & No & 58.33 & 5.86 & \multirow{2}{*}{.892} & \multirow{2}{*}{ NS } \\
FATE & Yes & 57.95 & 4.35 & & \\
& Non healed & 58.25 & 4.79 & \multirow{2}{*}{.905} & \multirow{2}{*}{ NS } \\
\hline
\end{tabular}

**Fisher exact

Table (3) Relation between sex and each of osteomyelitis, infection and healing among group 1 cases.

\begin{tabular}{|c|c|c|c|c|c|c|c|}
\hline & & \multicolumn{4}{|c|}{ Sex } & \multirow{3}{*}{$\mathbf{P}$} & \multirow{3}{*}{ Sig } \\
\hline & & \multicolumn{2}{|c|}{ Male } & \multicolumn{2}{|c|}{ Female } & & \\
\hline & & $\mathbf{N}$ & $\%$ & $\mathbf{N}$ & $\%$ & & \\
\hline \multirow[t]{2}{*}{ X-ray } & $\begin{array}{l}\text { No } \\
\text { osteomyelitis }\end{array}$ & 4 & $30.8 \%$ & 5 & $41.7 \%$ & \multirow[t]{2}{*}{.688} & \multirow[t]{2}{*}{ NS } \\
\hline & Osteomyelitis & 9 & $69.2 \%$ & 7 & $58.3 \%$ & & \\
\hline \multirow{2}{*}{$\begin{array}{l}\text { Infection } \\
\text { contained }\end{array}$} & No & 2 & $15.4 \%$ & 1 & $8.3 \%$ & \multirow{2}{*}{1.0} & \multirow{2}{*}{ NS } \\
\hline & Yes & 11 & $84.6 \%$ & 11 & $91.7 \%$ & & \\
\hline \multirow[t]{2}{*}{ FATE } & Non healed & 2 & $15.4 \%$ & 2 & $16.7 \%$ & \multirow{2}{*}{1.0} & \multirow{2}{*}{ NS } \\
\hline & Healed & 11 & $84.6 \%$ & 10 & $83.3 \%$ & & \\
\hline
\end{tabular}

**Fisher exact 
Table (4) Relation between age and each of osteomyelitis, infection and healing among group 2 cases.

\begin{tabular}{|c|c|c|c|c|c|}
\hline & \multicolumn{2}{|c|}{ Age } & \multirow{2}{*}{$\mathbf{P}^{*}$} & \multirow{2}{*}{ Sig } \\
\hline & & Mean & $\pm \mathrm{SD}$ & & \\
\hline \multirow[t]{2}{*}{ X-ray } & No osteomyelitis & 58.13 & 4.26 & \multirow{2}{*}{.858} & \multirow[b]{2}{*}{ NS } \\
\hline & Osteomyelitis & 57.78 & 5.19 & & \\
\hline \multirow{4}{*}{$\begin{array}{l}\text { Infection } \\
\text { contained } \\
\text { FATE }\end{array}$} & No & 59.25 & 4.03 & \multirow{2}{*}{.557} & \multirow{2}{*}{ NS } \\
\hline & Yes & 57.76 & 4.65 & & \\
\hline & Non healed & 59.25 & 4.03 & 557 & NS \\
\hline & Healed & 57.76 & 4.65 & & \\
\hline
\end{tabular}

*Student $\mathrm{t}$ test

Table (5) Relation between sex and each of osteomyelitis, infection and healing among group 2 cases.

\begin{tabular}{|c|c|c|c|c|c|c|c|}
\hline & & \multicolumn{4}{|c|}{ Sex } & \multirow[t]{3}{*}{$\mathbf{P} * *$} & \multirow[t]{3}{*}{ Sig } \\
\hline & & \multicolumn{2}{|c|}{ Male } & \multicolumn{2}{|c|}{ Female } & & \\
\hline & & $\mathbf{N}$ & $\%$ & $\mathbf{N}$ & $\%$ & & \\
\hline \multirow[t]{2}{*}{ X-ray } & No & 11 & $57.9 \%$ & 5 & $83.3 \%$ & \multirow[t]{2}{*}{.364} & \multirow[t]{2}{*}{$\mathrm{NS}$} \\
\hline & Osteomyelitis & 8 & $42.1 \%$ & 1 & $16.7 \%$ & & \\
\hline \multirow{2}{*}{$\begin{array}{l}\text { Infection } \\
\text { contained }\end{array}$} & No & 3 & $15.8 \%$ & 1 & $16.7 \%$ & \multirow[t]{2}{*}{1.0} & \multirow[t]{2}{*}{ NS } \\
\hline & Yes & 16 & $84.2 \%$ & 5 & $83.3 \%$ & & \\
\hline \multirow[t]{2}{*}{ FATE } & \multirow{2}{*}{$\begin{array}{l}\text { Non healed } \\
\text { Healed }\end{array}$} & 3 & $15.8 \%$ & 1 & $16.7 \%$ & \multirow[t]{2}{*}{1.0} & \multirow[t]{2}{*}{ NS } \\
\hline & & 16 & $84.2 \%$ & 5 & $83.3 \%$ & & \\
\hline
\end{tabular}

**Fisher exact

\section{Discussion}

There is an investigation distributed in 2018 at Egyptian diary of emergency clinic medication contrasting between negative weight wound treatment and customary dressing This examination was directed in the vascular medical procedure office at Al-Azhar college emergency clinics. Procedure: The examination included 50 patients randomized into two gatherings [25 patients for VAC treatment and 25 patients for customary dressing] experiencing diabetic foot wounds. Results: 6 of 25 [24\%] in the Conventional treatment bunch were females while 19 of 25 [76\%] in the Conventional treatment bunch were guys. 3 of 25 [12\%] in the NPWT bunch were females and 22 of 25 [88\%] were guys.

In our investigation we included 50 patients experiencing diabetic foot contamination randomized into two gatherings [ 25 patients for VAC treatment and 25 patients for silver dressing]. Results: 12 out of 25 [48\%] patients in the silver gathering were females though 13 out of 25 cases [52\%] were guys. In VAC. dressing bunch 19 out of 25 cases [76\%] were guys and 6 out of 25 cases [23\%] were females. In the Conventional treatment gathering, 21 of 25 [84\%] were over 60 years old. 20 of 25 [80\%] in the NPWT bunch were over 60 years old. In our examination we made every one of our investigations on patients matured from 50 to 65 years of age.

AL azhar study sets their proportions of examination on granulation tissue arrangement in seven days, medical clinic remain, and cost of every strategy while we make our estimations on size of the injury, volume of the injury, assessed season of wound recuperating and paces of cases required higher removal. In AL azhar study they put a few components of correlation between those two gatherings which are: 1-injury bed granulation following multi week of treatment, 2-granulation tissue rate after finish of the examination, 3-mean surface zone of wounds 4-rate of 2ndry higher removal. 5-time of emergency clinic remain till the injury is completely granulated. 6contrast between those 2 modalities in cost. Then again, in our investigation we looked at 1-size of the injury 2-volume of the injury 3-recuperating rates in every methodology 4-disease control 5-number of wounds required higher removal.

In Al Azhar study, wound size was estimated at introductory introduction and afterward after treatment. Prior to treatment, the mean surface zone of wounds in the NPWT bunch was $40.44 \mathrm{~cm} 2$, the Conventional treatment $38.52 \mathrm{~cm} 2$. After injury the board, mean surface zone of the diabetic injuries was $36.08 \pm 2.56$ $\mathrm{cm} 2$ in the NPWT gathering and $37.63 \pm 2.86 \mathrm{~cm} 2$ in the Conventional treatment. In our investigation wound size was evaluated at regular intervals. Mean injury size toward the start of the investigation in Vac. Gathering was $\pm 34 \mathrm{~cm} 2$ and was $\pm 29.5 \mathrm{~cm} 2$ in silver gathering in the wake of closure the investigation twisted size in Vac. Gathering and silver gathering were $\pm 3.4 \mathrm{~cm}$ and \pm 6.2 individually. Frequency of higher removals in AL azhar concentrate in VAC gathering and regular gathering were 5/25 [20\%] and $6 / 25[24 \%]$ separately. 
In our examination we found that in VAC. Gathering 21out of 25[84\%] cases have controlled disease though in silver gathering 22 out of 25 cases [88\%] have controlled contamination. Additionally, we analyzed paces of recuperating in the two gatherings it was $84 \%$ in the two gatherings and cases required higher removal were 4 cases in each gathering $16 \%$. In Al Azhar study,At the finish of the investigation, all out mean expense in customary dressing bunch was $1976 \pm 123$ EP contrasted with $2275 \pm 154$ EP in VAC gathering. In our investigation silver dressing costs 700 L.E every week in spite of the fact that Vac dressing costs 3000 L.E.

There was a distinction in the all out expense at last. we likewise looked at time required for complete injury mending wich was $36.4 \pm 11.14$ days in VAC. Gathering while it was $98.2 \pm 6.45$ days in silver gathering. In Al Azhar study they lead the correlation by another way, estimating time of emergency clinic remain till the injury was completely granulated and prepared for skin joining which was $22.87 \pm 7.62$ in NPWT contrasted with $32.53 \pm 10.17$ in the regular gathering.

There is an exceptionally factually critical distinction between normal term of emergency clinic remain and it is diminished fundamentally in vacuum dressing. [p-value $=0.02$ ] [7].

Likewise there is another investigation distributed in april,2019 in lord Abdel Aziz emergency clinic in Saudi Arabia. This investigation meant to think about the viability of the utilization of controlled delivery ionic silver hydrophilic dressing with that of $\mathrm{MH}$ impregnated dressings in patients with diabetic neuropathic plantar ulcers. Patients and Methods: This was a planned, twofold visually impaired, randomized relative clinical preliminary directed in diabetic foot care unit at the King Abdul Aziz Specialist Hospital in Taif, Saudi Arabia. Seventy-one patients were selected from January 2015 to December 2017.

Patients with neuropathic plantar ulcers were remembered for the examination with prohibition of ischemic and neuroischemic ulcers. Patients who met the incorporation rules of this examination were partitioned and randomized into two gatherings: Group I [honey group] and Group II [silver hydrogel group]; in both the gatherings after waste of any assortment and careful debridement of hyperkeratotic and necrotic tissues and flooding the ulcers, in Group I, MHimpregnated dressing containing $35 \mathrm{~g}$ of Unique Manuka Factor-13 was applied, and in Group II, controlled delivery ionic silver hydrophilic dressings were utilized to cover the ulcer. . In our investigation we included 50 patients experiencing diabetic foot disease randomized into two gatherings [25 patients for VAC treatment and 25 patients for silver dressing]. consideration measures were all diabetic foot wounds with age going between 50-65 years of age, the individuals who have noteworthy blood vessel stenosis and deprived for revascularization, venous ulcer, nonatherosclerotic infections, for example, burger's malady and vasculitis and the individuals who are on oral hypoglycemic medications as opposed to insulin were avoided from the examination.

Method of the investigation: All patients remembered for the examination will be submitted to appropriate history taking and clinical appraisal at that point blood tests for; CBC, HBA1c, fasting and post prandial glucose tests, serum creatinine, serum urea and swab culture test from the injury. X-beam will be attempted to the influenced appendage with routine blood vessel shading Doppler to all cases to prohibit critical blood vessel stenosis. The individuals who are with noteworthy stenosis will be precluded from the investigation. All patients will have prober careful debridement and wound water system utilizing typical saline $0.9 \%$ and povidone iodine, at that point they will be partitioned into 2 gatherings those in the principal gathering will have silver containing treatment a short time later. The subsequent gathering will have silver based dressing utilizing vacuum dressing. 12 out of 25 [48\%] patients in the silver gathering were females though 13 out of 25 cases [ $52 \%$ ] were guys.

In King abd al Azeez study The interim required for killing contamination, emergency clinic length of stay [LOS], and the interim of complete mending of the ulcers were the essential results. Optional result was to connect the interim of ulcer recuperating with span of diabetes, hemoglobin A1c, and nearness of nephropathy or neuropathy. Results: There was no huge distinction in the segment information, size of the ulcers, mean term of diabetes, and clinical and research facility information between both the gatherings [P > 0.05]. The interim to destroy disease and medical clinic LOS were diminished in the silver treatment bunch contrasted with nectar treatment gathering, yet the distinction doesn't arrive at a factual noteworthiness $[\mathrm{P}$ $>0.05]$; the table shows additionally that the interim required for complete ulcer recuperating was shorter in $\mathrm{MH}$ bunch than the silver hydrophilic dressing bunch $[\mathrm{P}>0.05$, insignificant $]$. In both the gatherings, the span of mending was fundamentally associated with the patient age, pretreatment level of $\mathrm{HbA} 1 \mathrm{c}$, pretreatment length of the ulcer, and the ulcer size; notwithstanding, there was no noteworthy connection with sex and term of diabetes. Ends: The current investigation checked the viability of $\mathrm{MH}$-impregnated dressings and the controlled delivery silver hydrophilic dressings in controlling injury contamination and advancing the total recuperating of neuropathic ulcers.In our examination wound size was assessed at regular intervals. Mean injury size toward the start of the investigation in Vac.

Gathering was $\pm 34 \mathrm{~cm} 2$ and was $\pm 29.5 \mathrm{~cm} 2$ in silver gathering in the wake of closure the investigation twisted size in Vac. Gathering and silver gathering were $\pm 3.4 \mathrm{~cm}$ and \pm 6.2 individually. In VAC. Gathering 21out of 25[84\%] cases have controlled contamination mean time required for annihilation of disease was $11.3 \pm 3.1$ days though in silver gathering 22 out of 25 cases [ $88 \%$ ] have controlled disease. The 
time required for silver gathering for destruction of contamination was 9.4 2.4 days. In King Abdel Aziz study, they measure time required for destruction of contamination and it was $11.1 \pm 2.3$ days for Manuka nectar dressing gathering and $10.9 \pm 2.25$ days for silver dressing bunch Also, we looked at paces of recuperating in the two gatherings it was $84 \%$ in the two gatherings and cases required higher removal were 4 cases in each gathering $16 \%$ [2] .
The current examination confirmed that vacuum dressing is more viable than silver dressing in diabetic foot wounds concerning mending time and medical clinic remain. There is no huge distinction in annihilation of contamination between the two modalities. In the matter of cost silver dressing is more modest than vacuum dressing in single week dressing however because of diminishing season of twisted mending there isn't contrast in complete expense was seen between those two modalities.

Case (1) 53 years old male patient with infected right heal after good debridement [vacuum group].

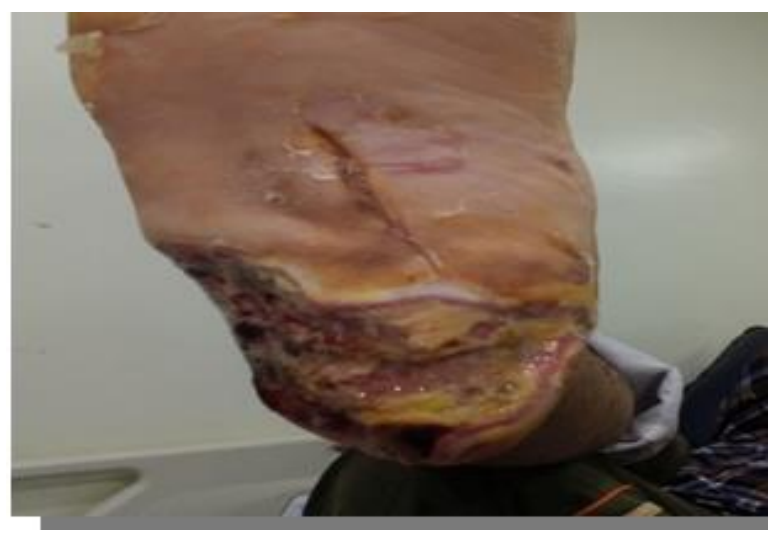

Fig (1) Before debridement

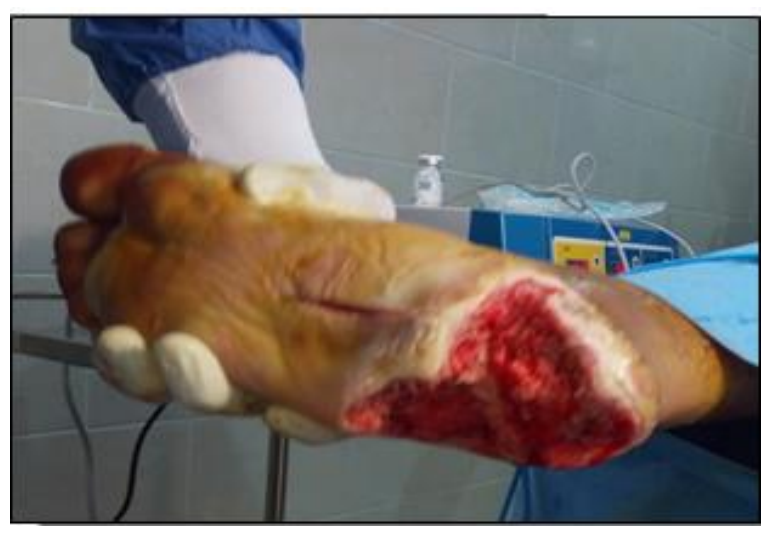

Fig (2) After debridement

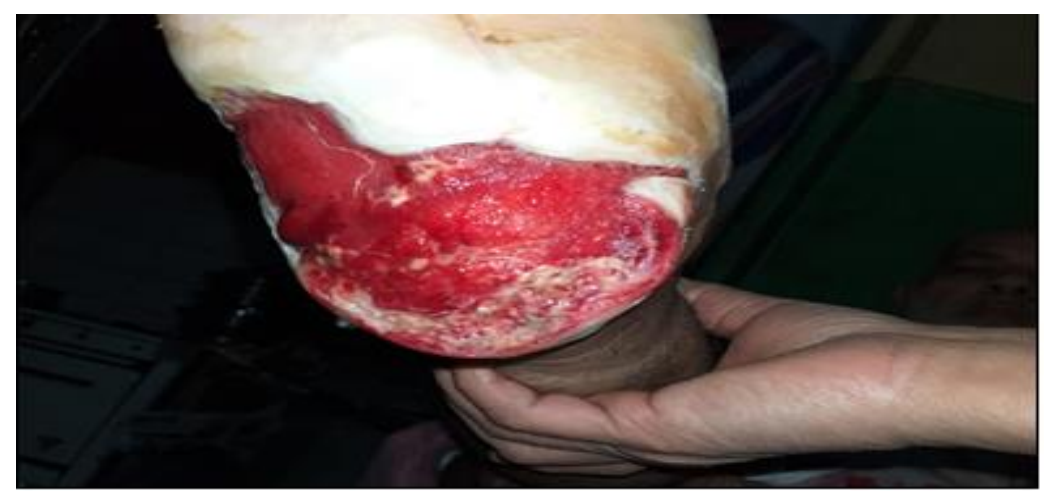

Fig (3) 2 weeks on vacuum dressing

Case (2) 56 years old female patient with infected heal and gangrenous patch [silver group].

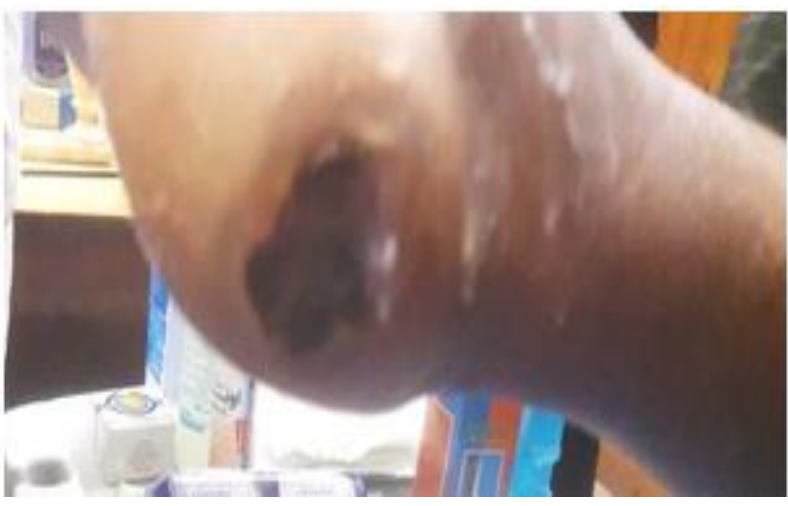

Fig (4.1) Before debridement

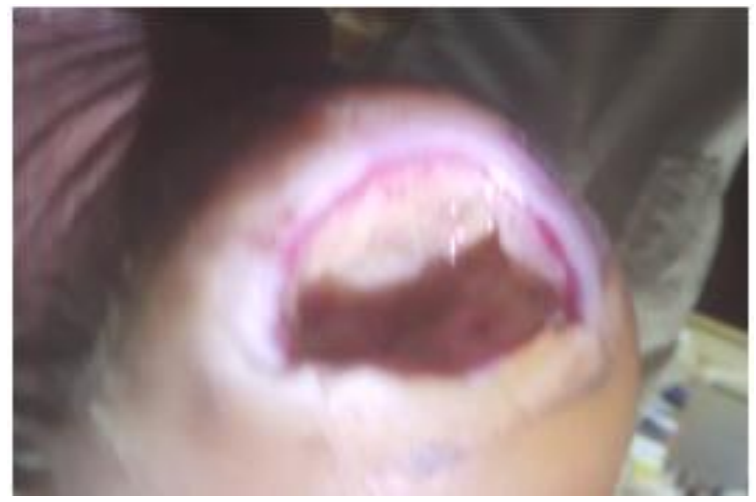

Fig ( 4.2 ) 1 Week after dressing 


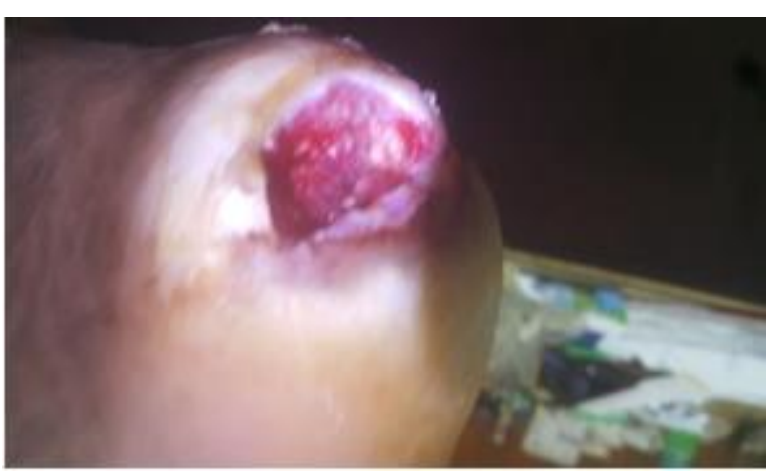

Fig (4.3) 2 weeks on silver dressing

\section{References}

[1] M. Y. Hasan, R.Teo, A. Nather, Negativepressure wound therapy for management of diabetic foot wounds: a review of the mechanism of action, clinical applications, and recent developments,Vol. 25(5), PP.213-225 2015

[2] M.Al Saeed, Prospective randomized comparison of controlled release ionic silver hydrophilic dressings and medicated honey-impregnated dressings in treating neuropathic diabetic foot ulce2019 Saudi J Health Sci, Vol.8, PP.25-30, 2019.

[3] R. P.Wilkes, D. V.Kilpad, Y. Zhao, Closed Incision Management With Negative Pressure Wound Therapy [CIM]: Biomechanics. Surgical Innovation, Vol.19(1), PP.67-75,2011.

[4] R.Satasia, K.solanki, S. katara, Conventional Dressings versus Vacuum-Assisted Closure and Hydrojel Dressing in the Management of Diabetic Foot Ulcers: A Prospective Case-Control Study:

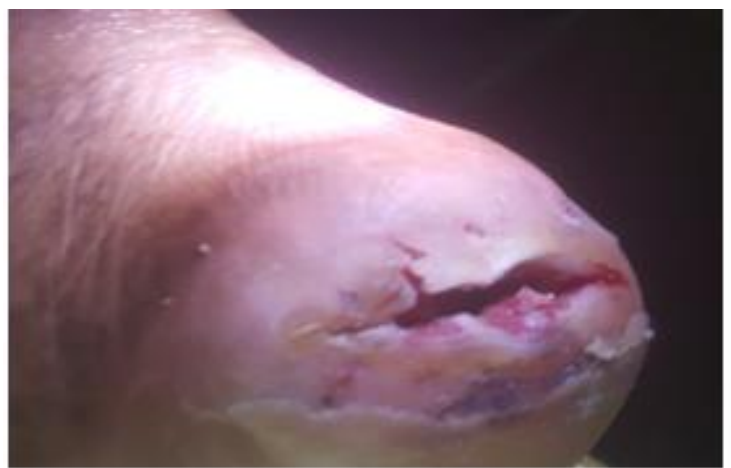

Fig (4.4) 40 days on silver dressing

Conventional Dressings versus Vacuum-Assisted Closure and Hydrojel Dressing. National Journal of Integrated Research in Medicine, Vol. 8(3), PP.130-134,2018.

[5] D . Jurić Vukelić, J. Jurić, Hydrocolloid Dressing Application in the Treatment of Chronic Wounds and Relation to Quality of Life. Acta Clin Croat,Vol.56(3), PP.544-549,2017.

[6] Y.Yang, H. Hu, Spacer fabric-based exuding wound dressing - Part I: Structural design, fabrication and property evaluation of spacer fabrics. Textile Research J., Vol.87(12), pp. 1469 $1480,2016$.

[7] Atef Bayoumi, Abdullah Al-Sayed, Abdullah AlMallah , Negative Pressure Wound Therapy Versus Conventional Dressing in Treatment of Diabetic Foot Wound . The Egyptian Journal of Hospital Medicine , Vol. 72 (3), PP. Page 40544059,2018 